\title{
Referências Teóricas em Análise Organizacional: um Estudo das Nacionalidades dos Autores Referenciados na Literatura Brasileira
}

\author{
Sylvia Constant Vergara \\ Mario Couto Soares Pinto
}

\begin{abstract}
ResUMO
O presente trabalho tem por objetivo continuar a pesquisa realizada por Vergara e Carvalho Jr. (1995) sobre a nacionalidade dos autores referenciados na literatura brasileira sobre organizações. Privilegia o período compreendido entre 1994 e 1998, apresenta os dados referentes a esse período, compara com aqueles obtidos na pesquisa anterior, que destacou o período compreendido entre 1989 e 1993 e, como conseqüência, apresenta dados referentes a uma década. Foram analisados 292 artigos e 6.812 referências bibliográficas constantes dos artigos. Tomou-se como fonte os anais do ENANPAD, a RAE, a RAP e a RAUSP. O estudo conclui que referências americanas têm sido as mais utilizadas. Os autores consideram que todo o esforço para esclarecer alguns pontos ainda sombrios que cercam as motivações, condições e limitações daqueles que são responsáveis pelo fortalecimento de uma teoria das organizações mais próxima das questões nacionais é urgente e necessário. Ele permitirá que se avalie o desenvolvimento desse campo no espaço brasileiro. $\mathrm{O}$ levantamento das nacionalidades dos autores referenciados é um passo nesse sentido.
\end{abstract}

Palavras-chaves: estudos organizacionais; referências; autores referenciados no Brasil; pesquisa bibliográfica.

\begin{abstract}
The main goal of this paper is to go on with the research started by Vergara and Carvalho Jr. (1995), which studied the nationality of the authors cited in brazilian organizational literature. It looks at the time gap between 1994 and 1998, shows the data concerning this period, and compares these data with those got by the earlier research. As that research investigated the 1989-1993 period, all together these two researches analyse an entire decade. There has been analised 292 articles and 6,812 citations. The sources were the proceedings of ENANPAD, RAE, RAP and RAUSP. The study concludes that American references have been the ones more used. The authors believe that one need to drive all efforts to elucidate some shadows areas that still lay over the motivations, conditions and constraints of those in charge to create an organization theory closer to our local questions. Such an effort will allow us check how developed is this arena in Brazil and, thus, this paper may be seen as a first step in this direction.
\end{abstract}

Key words: organizations studies; references; authors quoted in Brazil; bibliographical research. 


\section{INTRODUÇÃO}

No XIX Encontro Anual da Associação Nacional dos Programas de Pós-Graduação em Administração (ENANPAD), ocorrido em 1995, Vergara e Carvalho Jr. apresentaram um trabalho intitulado Nacionalidade dos Autores Referenciados na Literatura Brasileira sobre Organizações, que objetivava verificar o grau de apoio da produção científica brasileira em organizações, na literatura estrangeira, bem como levantar as principais razões para a utilização desse referencial.

Motivou-os a crença de que as referências bibliográficas utilizadas por um autor,

· são seus suportes teóricos de argumentação;

. revelam suas preocupações, preferências e suposições;

- podem ser indicadores da importância por ele atribuída à produção científica e ao contexto brasileiro;

- podem ser indicadores do seu condicionamento por outras culturas que não a brasileira.

Como resultado, o conjunto de referências bibliográficas utilizadas pelos autores brasileiros pode revelar, em maior ou menor grau, sua busca por uma análise organizacional sintonizada com a sociedade na qual é gerada.

A pesquisa focalizou o período compreendido entre 1989 e 1993. Elegeu quatro fontes representativas da produção nacional que se caracterizaram como a amostra da investigação, de natureza bibliográfica. Foram elas:

- Anais do Encontro Anual da Associação Nacional dos Programas de Pós-Graduação em Administração (ENANPAD).

. Revista de Administração de Empresas (RAE), da Fundação Getúlio Vargas de São Paulo.

- Revista de Administração Pública (RAP), da Fundação Getúlio Vargas do Rio de Janeiro.

. Revista de Administração (RAUSP), da Universidade de São Paulo.

Vergara e Carvalho Jr. (1995) concluíram que a produção científica brasileira na área de organizações estava fortemente apoiada em referencial estrangeiro, 
sobretudo estadunidense e, em menor destaque, apoiada em um grupo de quatro nacionalidades: francesa, britânica, alemã e canadense.

O presente trabalho objetiva dar continuidade à pesquisa mencionada, privilegiando os cinco anos que se lhe seguiram, isto é, o período compreendido entre 1994 e 1998. Apresenta os dados referentes a esse período e, sempre que pertinente, compara com aqueles obtidos no anterior (1989 a 1993). Tem-se, assim, a apresentação de dados referentes a uma década (1989 a 1998), no que concerne ao levantamento da nacionalidade dos autores referenciados pelos autores brasileiros de análise organizacional. Não apresenta, contudo, as razões para utilização deste ou daquele referencial, como o trabalho anterior. Esse levantamento está ainda sendo realizado.

O artigo está composto por seis seções, além desta introdução. Na primeira é apresentada revisão de literatura com capacidade para iluminar reflexões que a pesquisa bibliográfica provocou. Na segunda é apresentado o primeiro objeto da pesquisa, vale dizer, os artigos. A terceira trata do segundo objeto da pesquisa, ou seja, as referências utilizadas nos artigos. Na quarta seção são explicitados os critérios para a definição da nacionalidade dos autores referenciados nos artigos. A quinta seção apresenta a identificação das nacionalidades das referências. A sexta e última seção sumaria as descobertas, apresenta reflexões à guisa de conclusão e levanta questões para a continuação da pesquisa.

\section{REVISITANDO A LiterATURA}

No bojo das considerações acerca da utilização prioritária de referências estrangeiras por autores nacionais, a questão da identidade do grupo, no caso de pesquisadores brasileiros, apresenta-se como relevante. Em seu artigo sobre diversidade nas organizações, Nkomo e Cox Jr. (1999) ressaltam a importância do significado do conceito de identidade para o mapeamento das múltiplas dimensões do universo organizacional, tendência essa catalisada pelas interações forçadas pela mundialização da economia. Conforme asseveram, a teoria da identidade social preocupa-se com os efeitos da identidade do grupo sobre o comportamento humano, o que acarreta desdobramentos para o próprio grupo e para o todo social. Abordagens que envolvem o estudo da cultura, história ou política de um grupo, organização ou sociedade, bem como outras que procuram delimitar as circunstâncias em que conflitos ou estereótipos se desenvolvem, são alguns dos elos que nos permitem associar a identidade de um grupo com a dinâmica e as opções da vida de uma empresa. 
Seguindo uma linha de discussão semelhante, Aldefer e Smith (1982, p. 38) apontam para a existência de "grupos de identidade", em face dos quais o grupo opta por uma filiação psicológica. A relevância desta análise está na constatação de que tal filiação ao grupo de identidade antecede a do grupo organizacional, o que acaba por matizar tanto as experiências de trabalho comuns, quanto a própria visão de mundo de seus membros. É conhecido o trabalho de Hofstede (1984), em que se vincula a identidade de um grupo à sua nacionalidade, sob uma ótica etnológica. Afinal, o adequado entendimento do diferente passa, obrigatoriamente, pela certeza da própria identidade dos envolvidos.

Tomando o indivíduo como elemento de análise, ao invés do grupo, teríamos de dar conta de um debate equivalente, aquele que considera a si mesmo e o outro, nos termos encaminhados por Ricouer (1991). Entendendo o "si-mesmo como um outro", contraste que empresta título à sua obra, este autor percebe uma relação dialética entre mesmo e outro, que extrapola o antagonismo clássico entre tais denominações. Retomando a dimensão social, identidade e diversidade, aqui e lá, igual e diferente, são também dois opostos hegelianamente mesclados, fundidos em sua diferença. A esperada superação sintética de tese e antítese somente estaria apta a emergir, quando os termos se certificassem de que são distintos. Se tais termos são pesquisas, cenários, idéias ou fatos brasileiros e estadunidenses, por exemplo, então essa superação poderia estar ameaçada pela falta de uma discriminação, provavelmente mais dos primeiros do que dos últimos.

Reveladora indicação nos conferem Boyacigiller e Adler (1991), ao admitirem a existência de um "paroquialismo" nas pesquisas acadêmicas. O contexto global de tais investigações é apresentado por estes autores como dominado pelas questões estadunidenses, a despeito das significativas divergências contextuais existentes entre aquela realidade e as demais. Segundo suas palavras, este "paroquialismo é baseado na ignorância de outros caminhos" (Boyacigiller e Adler, p. 263).

$\mathrm{Na}$ realidade, tal empobrecimento pode também ser percebido no sentido inverso, os Estados Unidos deixando de receber virtuais subsídios para sua própria pesquisa, na medida em que a única realidade passível de discussão é aquela nascida dentro de suas fronteiras, e que só reconhece como válidos seus próprios métodos. Visto que o sistema é construído com apenas um tipo de tijolo, que deveria servir para todo o tipo de terreno e circunstância, não seria surpresa a existência de fragilidades importantes no desenvolvimento da teoria organizacional, conforme discute Pfeffer (1982).

Vale lembrar uma passagem em que Guerreiro Ramos (1983, p. 301) afirma que "embora constituído em nação independente, o Brasil teve que adotar os 
modelos institucionais dominantes no mundo, a fim de obter os requisitos essenciais para prosseguir em sua evolução". Dessa forma, aponta este autor, o fenômeno de mundialização traz como conseqüência a imitação daquilo que é estrangeiro por parte dos países marginais do capitalismo. O que daí deriva deveria ser motivo de preocupação pelos interessados em formar uma administração mais contextualizada e, talvez, menos universal.

Além de fatores ideológicos, que as considerações de Guerreiro Ramos (1983) sugerem, existem dados de realidade que talvez sirvam para justificar a utilização maciça de referências estrangeiras, concentradas em poucos países desenvolvidos, por pesquisadores do Terceiro Mundo. Boyacigiller e Adler (1991) desfraldam números que atestam o volume desproporcional da produção acadêmica dos países ricos, Estados Unidos à frente, quando comparada com a daqueles países que abrigam mais de dois terços da população mundial.

Se do ponto de vista quantitativo a produção e a pesquisa em administração fincaram suas raízes em solo rico, sob o aspecto qualitativo deve-se atentar para o fato de que a agenda hegemônica de discussão é, em larga maioria, definida por aqueles que detêm os principais meios de divulgação, os quais validam as regras de publicação e os parâmetros de aceitação (Boyacigiller e Adler, 1991).

Outro reforço a essa relação de pouco equilíbrio se dá na seara histórica. Afinal, entre nós, brasileiros, a construção do campo administrativo, forjado tanto pelas questões que uma economia em desenvolvimento suscita, quanto pelas pelejas havidas em salas de aula, mostrou-se indissociável dos modelos e das orientações estadunidenses (Bertero e Keinert, 1994).

Esses fatos não passaram despercebidos. A preocupação de pensadores brasileiros com o que se produz no universo acadêmico, relativo ao campo organizacional, merece nota. Machado-da-Silva et al. (1989) discutiram a produção acadêmica em administração pública. No ano seguinte, Machado-da-Silva, Cunha e Amboni (1990) asseveraram que o desenvolvimento de um campo de conhecimento pode ser avaliado observando-se sua produção mais recente. Baseados em tal crença, analisaram artigos na área de organizações no período compreendido entre 1985 e 1989, classificando-os por assunto e tema. Uma das conclusões a que chegaram refere-se à predominância, nos artigos analisados, do enfoque prescritivo sobre o analítico (Machado-da-Silva, Cunha e Amboni, 1990).

Bertero e Keinert (1994), por seu turno, dedicaram-se a analisar a produção de uma das principais revistas da área, a Revista de Administração de Empresas, publicada pela Fundação Getúlio Vargas de São Paulo, desde os idos de 1961 até 1993, constatando a íntima relação com temas estadunidenses e europeus. 
Vergara e Carvalho Jr. (1996) reapresentaram suas inquietações em relação ao tema, quando trataram das conseqüências que uma produção atrelada a outras realidades pode acarretar para a área receptora.

Evidências indicam que o mapeamento deste campo, ainda que não tenha origem recente, está longe de indicar sinais de exaustão. Dessa forma, um esforço que permita uma continuidade desse acompanhamento é fundamental para o esclarecimento de alguns pontos ainda sombrios que cercam as motivações, condições e limitações daqueles que são responsáveis pelo fortalecimento de uma teoria das organizações mais próxima das questões nacionais. É o que faremos a seguir.

\section{Os Artigos}

Para fins da proposta desse trabalho, foram analisados 292 artigos e, como pode ser visualizado na Tabela 1, 169 deles foram publicados nos anais dos ENANPADs, 29 na RAE, 69 na RAP e 25 na RAUSP.

Tal como na pesquisa anterior, para caracterizar os artigos publicados nas revistas como dizendo respeito à área de organizações, utilizaram-se critérios similares aos adotados no ENANPAD.

\section{Tabela 1: Total de Artigos da Área de Organizações Publicados nas Fontes Referenciadas}

\begin{tabular}{|l|c|c|c|c|c|c|}
\hline FONTE & 1994 & 1995 & 1996 & 1997 & 1998 & TOTAL \\
\hline ENANPAD & 18 & 21 & 57 & 33 & 40 & 169 \\
\hline RAE & 12 & 09 & 04 & 02 & 02 & 29 \\
\hline RAP & 08 & 14 & 15 & 13 & 19 & 69 \\
\hline RAUSP & 04 & 07 & 04 & 06 & 04 & 25 \\
\hline Total & 42 & 51 & 80 & 54 & 65 & 292 \\
\hline
\end{tabular}

No período anterior, foram identificados 165 artigos; logo, no período agora sob análise, houve acréscimo de mais de $70 \%$. O divulgado aumento do número de trabalhos apresentados no ENANPAD e a diminuição da periodicidade da RAP podem corroborar a descoberta aqui explicitada. 
Vale ressaltar também que, à exceção das publicações do ENANPAD, as quais já se apresentam divididas por áreas, nas demais publicações consideradas tal classificação nem sempre era indiscutível.

Dessa forma, visto que muitos temas da área são nitidamente multidisciplinares, alguns artigos poderiam ter sido contabilizados em outras regiões que compartilham fronteiras com organizações, tais como recursos humanos, estratégia ou, por vezes, administração pública.

Nesses casos, optou-se pela sua inserção na área de organizações, o que também contribuiu para a ampliação da base de análise. Visto que a maioria dos artigos analisados é oriunda do ENANPAD, na proporção aproximada de 60/40, a decisão de considerar textos com tais características não causou distorções significativas ao resultado final.

As publicações identificadas revelaram a instituição à qual estão vinculados seus autores. Para definição de tal vinculação foram adotados os seguintes critérios:

- quando o autor está vinculado a mais de uma instituição, optou-se pela primeira que ele referencia;

- quando há mais de um autor e todos são professores, escolheu-se o primeiro autor mencionado;

- quando há mais de um autor, porém um é professor e o outro, aluno, optou-se pelo professor, pois sua vinculação é óbvia.

A Tabela 2, a seguir, sintetiza a identificação feita.

Observe-se que a FGV de São Paulo, primeira colocada na classificação, edita a RAE; a USP, terceira colocada, edita a RAUSP e a FGV do Rio de Janeiro, sétima colocada, edita a RAP.

No levantamento das vinculações foi possível observar que grande parte dos autores da RAE está vinculada à FGV de São Paulo. A RAP e a RAUSP, no entanto, abrem mais espaços para autores de outras instituições. Nessa linha, o ENANPAD é o espaço mais democrático, e a maioria das 61 instituições incluídas na entrada genérica de Outras, na tabela anterior, encontrou ali possibilidade de publicação.

Levantados os artigos, procedeu-se ao arrolamento das referências neles utilizadas. 
Tabela 2: Número de Artigos por Instituição e por Ano

\begin{tabular}{|l|c|c|c|c|c|c|}
\hline Instituição/Ano & 1994 & 1995 & 1996 & 1997 & 1998 & TOTAL \\
\hline FGV-SP & 08 & 04 & 12 & 03 & 05 & 032 \\
\hline UFRGS & 03 & 07 & 04 & 06 & 11 & 031 \\
\hline USP & 09 & 11 & 07 & 02 & 01 & 030 \\
\hline PUC-Rio & 01 & 06 & 07 & 05 & 04 & 023 \\
\hline UFMG & 02 & 03 & 06 & 06 & 04 & 021 \\
\hline UFBA & 04 & 02 & 06 & 01 & 04 & 017 \\
\hline FGV-RJ & 03 & 04 & 01 & 05 & 04 & 017 \\
\hline UFSC & 02 & 02 & 03 & 05 & 03 & 015 \\
\hline UFRJ & 02 & 02 & 05 & 01 & 02 & 012 \\
\hline UFPE & - & 02 & 05 & 01 & 03 & 011 \\
\hline UnB & 01 & 03 & 02 & - & 05 & 011 \\
\hline UFRN & - & - & 02 & 02 & 02 & 006 \\
\hline PUC-SP & 01 & 01 & - & 03 & - & 005 \\
\hline Outras & 04 & 08 & 19 & 13 & 17 & 061 \\
\hline Total & 40 & 55 & 79 & 53 & 65 & 292 \\
\hline
\end{tabular}

\section{As ReferênCias}

A análise dos 292 artigos pesquisados revelou 6.812 referências bibliográficas, distribuídas por ano e por fonte, como pode ser visualizado na Tabela 3.

No período anterior foram levantadas 2.949 referências. Se se compara esse total com o atual (6.812), pode-se perceber que houve um aumento de mais de $130 \%$, condizente com o aumento do número de artigos.

No que se refere ao ENANPAD, percebe-se um significativo incremento da quantidade das referências apresentadas de 1995 para 1996, como resultado de um aumento proporcional do número de artigos publicados de um ano para o outro. Ainda que apresentando uma queda no número de textos publicados de 
1996 para 1997, o patamar de referências não cedeu. Esse fato deveu-se a um aumento do número médio de referências por artigo no ENANPAD de 1997, que retomou sua média histórica no ano seguinte.

Tabela 3: Total de Referências por Ano e por Fonte

\begin{tabular}{|c|c|c|c|c|c|}
\hline ANO/FONTE & ENANPAD & RAE & RAP & RAUSP & TOTAL \\
\hline 1994 & 0351 & 0083 & 0162 & 0184 & 0780 \\
\hline 1995 & 0391 & 0136 & 0208 & 0202 & 0937 \\
\hline 1996 & 1335 & 0076 & 0417 & 0048 & 1876 \\
\hline 1997 & 1343 & 0083 & 0147 & 0150 & 1723 \\
\hline 1998 & 0999 & 0055 & 0379 & 0063 & 1496 \\
\hline Total & 4419 & 0534 & 1313 & 0546 & 6812 \\
\hline
\end{tabular}

Identificados os artigos e as referências, procedeu-se ao levantamento da nacionalidade dos autores referenciados, de acordo com o critério a seguir apresentado.

\section{Critérios para DefiniçÃo da Nacionalidade dos Autores Referenciados Nos Artigos}

Tal como na pesquisa de Vergara e Carvalho Jr. (1995), definiu-se referência como o autor e sua respectiva obra, seja livro ou artigo.

Também tal como na investigação de Vergara e Carvalho Jr. (1995), a nacionalidade foi entendida como a do autor, independentemente do país no qual a obra foi publicada. Às vezes, nos artigos objeto da presente análise, foram citadas várias obras de um mesmo autor. Cada uma delas foi computada como uma referência.

A definição da nacionalidade do autor seguiu os critérios adotados na pesquisa de Vergara e Carvalho Jr. (1995), a saber:

- País de nascimento do autor e no qual ele teve sua formação acadêmica, desenvolveu suas atividades e publicou suas obras. 
. País do qual o autor recebeu influência predominante, até a época da elaboração de seu trabalho.

. País onde o autor está radicado. Contempla autores que foram estudar em outro país e lá permaneceram, bem como autores sem produção relevante em seu país de origem e que passaram a publicar em outro país, no qual residem.

. País de nascimento de autores considerados notáveis e que tinham produção relevante antes de se radicarem em outros países. É o caso, por exemplo, de Marcuse, DaMatta, Guerreiro Ramos, Marx, entre outros. Se é razoável supor que tais autores tenham sofrido influência cultural dos países nos quais se radicaram, é também razoável supor que a influência dominante tenha sido a da cultura de seu país de origem.

Nem sempre tais critérios apresentaram-se claramente delimitados, havendo casos em que o autor atendia, conflitantemente, a dois ou mais dos itens acima listados. Estes casos foram, na verdade, exceções; com eles a classificação do autor numa nacionalidade observou o tema abordado em sua contribuição, caso este estivesse voltado para a realidade de um país específico, as preocupações mais freqüentes do autor e, finalmente, o bom senso.

Identificados os artigos e levantadas as referências, à luz dos critérios adotados, procedeu-se à identificação da nacionalidade dos autores referenciados nos artigos. É o que se verá a seguir.

\section{IDENTIFICAÇÃo dA NACIONALIDADE DAS ReFERÊNCIAS}

Como mencionado, foram analisadas 6.812 referências. Desse total foi possível identificar a nacionalidade de 5.787 , o que significa quase $85 \%$ do total. Um esforço adicional de pesquisa, que fosse capaz de reconhecer a nacionalidade dos demais $15 \%$, mostrou-se penoso e demorado demais para os objetivos deste trabalho, além de não enriquecer significativamente suas conclusões. Ademais, esse percentual é significativamente menor do que os $25 \%$ constantes na pesquisa anterior.

A rigor, a grande maioria dessas referências é, provavelmente, estrangeira, devido a diversas características observadas: nome do autor, idioma do título de sua obra, periódico ou a editora que a publicou e local da publicação. De toda a maneira, para o presente estudo as nacionalidades foram tomadas como não identificadas. 
Mesmo que todos os autores não identificados pertencessem à mesma nacionalidade, o que é fortemente improvável, ainda assim os Estados Unidos seriam os maiores contribuintes individuais de referências estrangeiras. O que talvez viesse a ocorrer, se o esforço de identificação fosse levado a termo, seria uma suave troca de posição entre aqueles países que se situam nas posições intermediárias, tais como Grã-Bretanha, França ou Canadá. O mais provável, contudo, é que a maioria das referências não identificadas pertença, também, ao grupo de autores estadunidenses.

A Tabela 4, a seguir, sintetiza as identificações.

Tabela 4: Número e Percentual de Referências por Nacionalidade e por Fonte no Período 1993-1998

\begin{tabular}{|l|c|c|c|c|c|c|}
\hline País / fonte & ENANPAD & RAE & RAP & RAUSP & Total & $\%$ \\
\hline US A & 1643 & 0211 & 0261 & 0175 & 2290 & 33,62 \\
\hline Brasil & 1441 & 0089 & 0439 & 0136 & 2105 & 30,90 \\
\hline Inglaterra & 0302 & 0052 & 0071 & 0048 & 0473 & 6,94 \\
\hline França & 0172 & 0047 & 0103 & 0030 & 0352 & 5,17 \\
\hline Canadá & 0107 & 0007 & 0042 & 0007 & 0163 & 2,39 \\
\hline Alemanha & 0073 & 0020 & 0059 & 0010 & 0162 & 2,38 \\
\hline Japão & 0010 & 0009 & 0034 & 0009 & 0062 & 0,91 \\
\hline Austrália & 0020 & 0004 & 0007 & 0004 & 0031 & 0,46 \\
\hline A. Latina & 0022 & 0004 & 0003 & 0002 & 0031 & 0,46 \\
\hline Holanda & 0009 & 0002 & 0003 & 0003 & 0016 & 0,23 \\
\hline Africanos & 0008 & 0000 & 0000 & 0000 & 0008 & 0,12 \\
\hline Outros & 0034 & 0016 & 0031 & 0012 & 0093 & 1,37 \\
\hline Não ident. & 0578 & 0077 & 0260 & 0110 & 1025 & 15,05 \\
\hline Total & 4419 & 0534 & 1313 & 0546 & 6812 & 100,0 \\
\hline \% & 63,27 & 9,45 & 18,57 & 8,71 & 100,0 & \\
\hline
\end{tabular}


Para o cálculo do percentual de cada nacionalidade foram incluídas as não identificadas, tal como no período anterior.

Os dados revelam que as referências americanas aumentaram levemente de um período para o outro (de 31,88\% para 33,62\%). Dessa forma, continuam sendo as mais citadas, predominando, portanto, na década considerada $(33,09 \%)$.

Seguem-se-lhes as brasileiras, que aumentaram significativamente (de 21,70\% para 30,90\%). A manutenção do patamar das referências americanas e o aumento das brasileiras serão uma sinalização de busca de sintonia com a realidade na qual as análises organizacionais são produzidas? De todo o modo, tal como no período anterior, as referências brasileiras permanecem em segundo lugar na década $(28,12 \%)$.

A seguir vêm as referências britânicas e as francesas; no entanto as referências britânicas aumentaram no segundo período (de 5,49\% para 6,94\%) e as francesas diminuíram um pouco (de $5,70 \%$ para $5,17 \%$ ), provocando a troca de posição entre si. Na década, portanto, referências britânicas (6,51\%) são maiores que as francesas $(5,32 \%)$.

Em seguida vêm as referências alemãs e as canadenses, que diminuíram. As alemãs passaram de $3,80 \%$ para $2,38 \%$ e as canadenses de $2,44 \%$ para $2,39 \%$. Apesar de ambas terem diminuído, a posição entre elas mudou. Na década, a Alemanha responde por 2,80\% das referências e o Canadá por 2,41\%. Na realidade, mais importante do que tais alterações de posição, que podem ter ocorrido por variação estatística aceitável, é a constatação de que as ordens de grandeza não se modificaram ao longo de toda a década.

Um olhar sobre a Tabela 4 permite perceber que o conjunto das referências estrangeiras atinge o número 4.707 e representa $69,10 \%$ da totalidade de referências, o que pode revelar ausência de paroquialismo na produção dos autores dos artigos aqui considerados. As referências estrangeiras são maiores no ENANPAD $(63,27 \%)$, seguindo-lhe a RAP $(18,57 \%)$, a RAE $(9,45 \%)$ e a RAUSP $(8,71 \%)$.

A Tabela 5 permite visualizar as posições das nacionalidades das referências mais citadas nos dois períodos, separadamente, e na década. Salta aos olhos a relevância das referências estadunidenses diante das demais e, da mesma forma, a pouca mudança dos números de cada país, à exceção do Brasil. 
Tabela 5: As Seis Nacionalidades Predominantes no Período 1989-1993, no Período 1994-1998 e na Década (1989-1998)

\begin{tabular}{|l|c|c|c|}
\hline \multicolumn{1}{|c|}{ País } & $1989-1993(\%)$ & $1994-1998(\%)$ & Década $(\%)$ \\
\hline USA & 31,88 & 33,62 & 33,09 \\
\hline Brasil & 21,70 & 30,90 & 28,12 \\
\hline Inglaterra & 5,49 & 6,94 & 6,51 \\
\hline França & 5,70 & 5,17 & 5,32 \\
\hline Alemanha & 3,80 & 2,38 & 2,80 \\
\hline Canadá & 2,44 & 2,39 & 2,41 \\
\hline
\end{tabular}

No conjunto das referências estrangeiras, sem levar em consideração as não identificadas, o percentual de participação das estadunidenses é, portanto, 62,19\%, das britânicas $12,85 \%$, das francesas $9,56 \%$, das alemãs $4,40 \%$ e das canadenses $4,43 \%$, conforme pode ser visualizado na Tabela 6 . Facilmente pode-se perceber a robustez das referências estadunidenses em relação ao conjunto das estrangeiras.

Tabela 6: Participação das Referências Estadunidenses, Britânicas, Francesas, Canadenses e Alemãs em Relação à Totalidade das Referências Estrangeiras (\%) no Período Compreendido entre 1994 e 1998

\begin{tabular}{|l|c|c|c|c|c|c|}
\hline Ano/país & USA & Inglaterra & França & Alemanha & Canadá & Outros \\
\hline 1994 & 52,44 & 15,33 & 16,89 & 6,22 & 3,11 & 6,01 \\
\hline 1995 & 66,28 & 10,07 & 07,96 & 6,09 & 3,75 & 5,85 \\
\hline 1996 & 62,17 & 11,63 & 09,66 & 2,56 & 6,11 & 7,87 \\
\hline 1997 & 67,81 & 09,68 & 08,71 & 3,87 & 3,34 & 6,59 \\
\hline 1998 & 59,00 & 17,76 & 07,31 & 4,87 & 4,64 & 6,41 \\
\hline Total & 62,19 & 12,85 & 09,56 & 4,40 & 4,43 & 6,57 \\
\hline
\end{tabular}

Ao resgatar os resultados da pesquisa referentes ao período 1989-1993, verifica-se que a participação estadunidense e a britânica aumentou, a francesa, a alemã e a canadense diminuiu, bem como diminuiu a participação dessas cinco 
nacionalidades em relação às demais referências estrangeiras. A década, contudo, conforme mostra a Tabela 7, apresenta as mesmas características: predomínio das referências estadunidenses em relação às estrangeiras e predomínio das referências americanas, britânicas, francesas, alemãs e canadenses, quando comparadas às demais estrangeiras.

\section{Tabela 7: Participação das Referências Estadunidenses, Britânicas, Francesas, Canadenses e Alemãs em Relação à Totalidade das Referências Estrangeiras (\%) na Década Considerada}

\begin{tabular}{|l|c|c|c|c|c|c|}
\hline Período/País & USA & Inglaterra & França & Alemanha & Canadá & Outros \\
\hline $1989-1993$ & 59,91 & 10,33 & 10,71 & 7,14 & 4,59 & 7,32 \\
\hline $1994-1998$ & 62,19 & 12,85 & 09,56 & 4,40 & 4,43 & 6,57 \\
\hline Década & 61,05 & 11,59 & 10,13 & 5,77 & 4,51 & 6,95 \\
\hline
\end{tabular}

No levantamento das referências foi possível observar que há autores estrangeiros, por nacionalidade, mais citados. É assim que nas referências canadenses predominam os autores da École des Hautes Études Commerciales (HEC), principalmente Jean-François Chanlat; nas referências australianas predomina Stewart Clegg; nas holandesas, Geert Hofstede e nas alemãs praticamente só autores clássicos.

É de supor-se que, sem a presença desses autores, algumas nacionalidades quase não seriam lembradas. Disso talvez possamos apreender que a relação entre os pesquisadores brasileiros e um desses países seja circunstancial, ao contrário do que ocorre com os Estados Unidos, Grã-Bretanha ou França, onde existe uma gama interminável de autores citados.

Outras descobertas foram possíveis em relação ao período compreendido entre 1994 e 1998. Por exemplo:

- Somadas as referências em língua inglesa (estadunidenses, britânicas e australianas), verifica-se que tal soma responde por $75,88 \%$ das referências estrangeiras, excluindo-se as não identificadas.

- Referências japonesas só aparecem em poucos artigos, especialmente naqueles nos quais um dos autores é japonês. Elas aumentaram de 0,37\% (1989 a 1993 ) para 0,91\% (1994 a 1998); porém esse aumento não é resultado de uma diluição do interesse por vários autores dos artigos aqui sob análise, e sim devido a alguns trabalhos específicos nos quais o tema central, em alguma medida, necessitava de tais embasamentos. 
. As referências latino-americanas, tal como no período anterior, continuam inexpressivas.

- Como a Tabela 4 demonstrou, está nos artigos publicados nos anais do ENANPAD o maior percentual de referências brasileiras $(68,46 \%)$, seguido da RAP (20,85\%), da RAUSP (6,46\%) e da RAE (4,23\%). Nesta última encontra-se, portanto, o menor percentual.

Adicionalmente, no levantamento das referências foi possível observar que os anais do ENANPAD revelam artigos cuja maioria é resultado de pesquisa de campo realizada no Brasil. Estaria sendo o ENANPAD o forum privilegiado para apresentação de trabalhos direcionados à realidade brasileira?

A leitura dos artigos permitiu também identificar as auto-referências por ano e por revista. A Tabela 8 o demonstra.

Tabela 8: Auto-Referências por Ano e por Revista

\begin{tabular}{|l|c|c|c|c|c|}
\hline Ano/fonte & ENANPAD & RAE & RAP & RAUSP & Total \\
\hline 1994 & 010 & 005 & 009 & 004 & 028 \\
\hline 1995 & 013 & 011 & 003 & 009 & 036 \\
\hline 1996 & 051 & 000 & 004 & 004 & 059 \\
\hline 1997 & 026 & 005 & 015 & 006 & 052 \\
\hline 1998 & 040 & 001 & 044 & 004 & 089 \\
\hline Total & 140 & 022 & 075 & 027 & 264 \\
\hline$\%$ & 3,17 & 4,12 & 1,68 & 4,95 & \\
\hline
\end{tabular}

Como se pode ver, em termos absolutos, são os anais do ENANPAD que abrigam artigos com maior número de auto-referências; a RAE é a publicação que abriga o menor número; porém, quando estes números são ponderados pela quantidade de artigos publicados em cada revista, o quadro transforma-se radicalmente. Assim, a RAUSP tem uma relação de $4,95 \%$, a RAE de $4,12 \%$, os anais do ENANPAD de 3,17\% e a RAP tem 1,68\%. Apesar das diferenças não serem marcantes, isso leva a supor que o ENANPAD, além de mais democrático, apresenta textos mais voltados a referências externas do que, por exemplo, a RAUSP e a RAE. 


\section{Para Concluir}

O presente artigo propôs-se a estudar a evolução das referências utilizadas por autores nacionais de administração, vinculados à área de organizações, e que publicaram trabalhos no ENANPAD, na RAE, na RAP e na RAUSP no período de 1994 e 1998. A idéia central do artigo é dar continuidade à pesquisa iniciada por Vergara e Carvalho Jr. (1995), que concluíram trabalho semelhante para o período compreendido entre 1989 e 1993, mapeando, dessa forma, uma década de publicações nesse campo.

Deste esforço, algumas conclusões são visíveis. A primeira delas é que as referências de origem estadunidense são as mais utilizadas, em cada período estudado e, por conseqüência, nos dez anos somados. Seu peso em relação às demais referências estrangeiras aumentou, se considerados os dois estudos, o que pode significar que os autores nacionais se sentem confortáveis e seguros na sua utilização.

A introdução de meios eletrônicos de pesquisa nos últimos anos aparentemente não alterou a predisposição de buscarem-se tais referências. Essa consideração é aceitável, se se observa que, no trabalho de Vergara e Carvalho Jr. (1995), uma das justificativas fornecidas pelos entrevistados era a facilidade de acesso às referências estadunidenses. Visto que o quadro não se alterou, apresentando mesmo um ligeiro aumento desse predomínio, se esse fator é relevante, apenas direcionou mais ainda essa preferência.

Outra constatação, similar àquela encontrada na primeira pesquisa, é que referências britânicas e francesas têm seu espaço, mais aquelas do que essas, assim como as canadenses, apesar de seu peso ter-se reduzido, conforme os dados deste trabalho. Supõe-se que as ligações dos pesquisadores brasileiros com estes três países (Grã-Bretanha, França e Canadá) não sejam desprezíveis, ainda que estejam longe de representar qualquer sombra à hegemonia dos Estados Unidos.

Por seu turno, as referências alemãs são praticamente desconhecidas, e só são utilizadas em trabalhos específicos, no mais das vezes atreladas a expoentes clássicos, tais como Max Weber ou Karl Marx e, mais recentemente, Jürgen Habermas. Diretamente associadas à realidade organizacional, pouco foi observado, talvez pelo desconhecimento da língua ou talvez pela pouca afinidade que pesquisadores nacionais guardam das direções germânicas. Igualmente, os demais países relevantes para os brasileiros, como o Japão, por ser a segunda maior economia do mundo, ou os latino-americanos, por sua proximidade e afinidade, não passam de uns poucos casos isolados. O mesmo pode ser dito de referências relacionadas a países não tão distantes, seja por seus hábitos, seja pelos idiomas, tais como Espanha e Itália, ambos praticamente ignorados. 
O ponto de destaque deste trabalho, contudo, está relacionado à presença maior dos autores nacionais como referência. Pelo significativo aumento da produção acadêmica nesse período e pelo grande volume de referências analisadas, um aumento de mais de $40 \%$ na participação de autores nacionais (de $21,7 \%$ para $30,9 \%$ ) merece confiança e deve ser ressaltado.

Entende-se ser o aumento de referências brasileiras um indício de que algo positivo está em andamento na pesquisa acadêmica brasileira, dentro da área considerada. Em primeiro lugar, essa maior vinculação a referências locais pode ser um sinal de que a qualidade se está aprimorando, quando comparada com a de outros países. Afinal, é de supor-se que nenhum pesquisador confiaria seus alicerces a referências duvidosas. Em segundo, podemos imaginar uma proximidade maior entre pesquisa e realidade nacional. Essa associação vem da constatação de que referências estrangeiras ou têm preocupação local, e nesse caso de pouco nos adiantam, ou apresentam uma proposta universal, o que a faria menos precisa. Em ambos os casos, a transliteração nem sempre é adequada às problemáticas nacionais.

Todavia esses resultados encontrados ainda são precários. Muito deve ser feito no sentido de que melhor se possa entender as motivações que direcionam tantos e tão bons pensadores brasileiros a ignorar, em seus trabalhos, os países citados, bem como a usar com tamanha opulência as referências estadunidenses. Sem dúvida, razões históricas existem para isso, e algumas foram aqui tangenciadas. Ainda assim, o fato de que um dia foi dessa forma, e de que hoje ainda funciona desse jeito, não deve ser obstáculo para mudanças futuras, pois nesse campo não há lugar para determinismos, quaisquer que sejam suas colorações.

Outra direção que deve ser investigada é o impacto dos meios eletrônicos de pesquisa nesse cenário. Se, por um lado, o lugar em que essa ferramenta está mais desenvolvida é justamente nos Estados Unidos, por outro existe um sêmen revolucionário presente, e que talvez possa alterar esse quadro, ampliando as possibilidades de pesquisa. Visto que a maioria das universidades brasileiras já dispõe, em maior ou menor grau, desse recurso, é factível supor que alguma alteração possa ocorrer nesse equilibramento.

Por fim, urge analisar os perfis das obras aqui publicadas, e do acesso que os pesquisadores menos conhecidos dispõem para exibir seus trabalhos. Números superficiais sugerem que nem todas as revistas disponibilizam seus espaços igualmente a todo o espectro de autores nacionais. Se isso ocorre por uma carência de maturidade do pesquisador, ou da revista, é um fato que mereceria ser pensado. De qualquer forma, um arejamento que exponha as fragilidades do pensamento hegemônico, seja ele estadunidense ou brasileiro, é sempre bem-vindo. 


\section{ReFERÉNCIAS BibLIOGRÁfICAS}

ALDEFER, C. P.;

SMITH, K. K.

Studying intergroup relations embedded in organizations. Administrative Science Quarterly, v. 27, 1982.

BERTERO, C. O.;

KEINERT, T. M. M.

A evolução da análise organizacional no Brasil (1961-93). Revista de Administração de Empresas, v. 36, n. 3, 1994.

BOYACIGILLER, N.;

ADLER, N.

The parochial dinosaur: organizational science in a global context. Academy of Management Review, v. 16, n. 2, 1991.

GUERREIRO RAMOS, A.

Administração e contexto brasileiro. Rio de Janeiro: FGV, 1983.

HOFSTEDE, G.

The cultural relativity of the quality of life concept. Academy of Management Review, v. 9, n. $2,1984$.
MACHADO-DA-SILVA, C. L. et al.

Produção acadêmica em administração pública: período 1983/88. In: XIII ENCONTRO ANUAL DA ANPAD (1989: Belo Horizonte). Anais... Belo Horizonte: ANPAD, 1989.

MACHADO-DA-SILVA, C. L.;

CUNHA,V. C.;

AMBONI, N.

Organizações: o estado da arte da produção acadêmica no Brasil. In: XIV ENCONTRO ANUAL DA ANPAD (1990: Florianópolis). Anais... Florianópolis: ANPAD, 1990.

NKOMO, S. M.;

COX JR., T.

Diversidade e identidade nas organizações. In: CLEGG, S. R.; HARDY, C.; NORD, W. R. (Orgs.). Handbook de estudos organizacionais. São Paulo: Atlas, 1999. v. 1.

PFEFFER, J.

Organizations and organization theory. London: Pitman, 1982.

RICOUER, P.

O si-mesmo como um outro.

São Paulo: Papirus, 1991. 
VERGARA, S.;

CARVALHO JR., D.

Nacionalidade dos autores referenciados na literatura brasileira sobre organizações. Revista Brasileira de Administração Contemporânea, v. 1, 1995.
Refletindo sobre as possíveis conseqüências da análise organizacional apoiada em referências estrangeiras. Revista de Administração de Empresas, v. 30, n. 6, 1996. 